Supporting information for

\title{
Comparative Effects on Recrystallization of Melt-Memory and Liquid-Liquid Phase Separation in Ziegler-Natta and Metallocene Ethylene Copolymers with Bimodal Comonomer Composition Distribution
}

Minqiao Ren, Xuejian Chen, Yuan Sang, Rufina G. Alamo*

Department of Chemical and Biomedical Engineering, FAMU/FSU College of Engineering, 2525 Pottsdamer St., Tallahassee FL 32310, USA
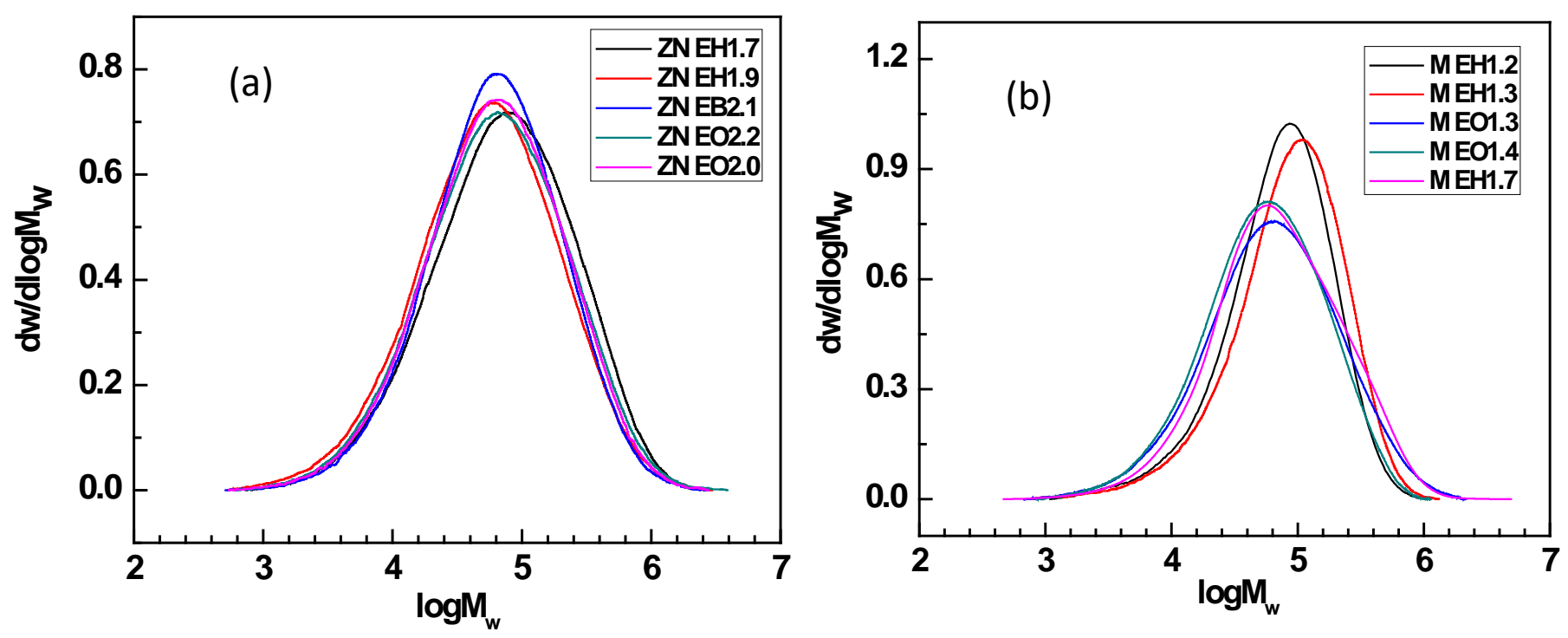

Figure S1. GPC profiles for LLDPEs synthesized with (a) Ziegler Natta and (b) metallocene catalysts. 


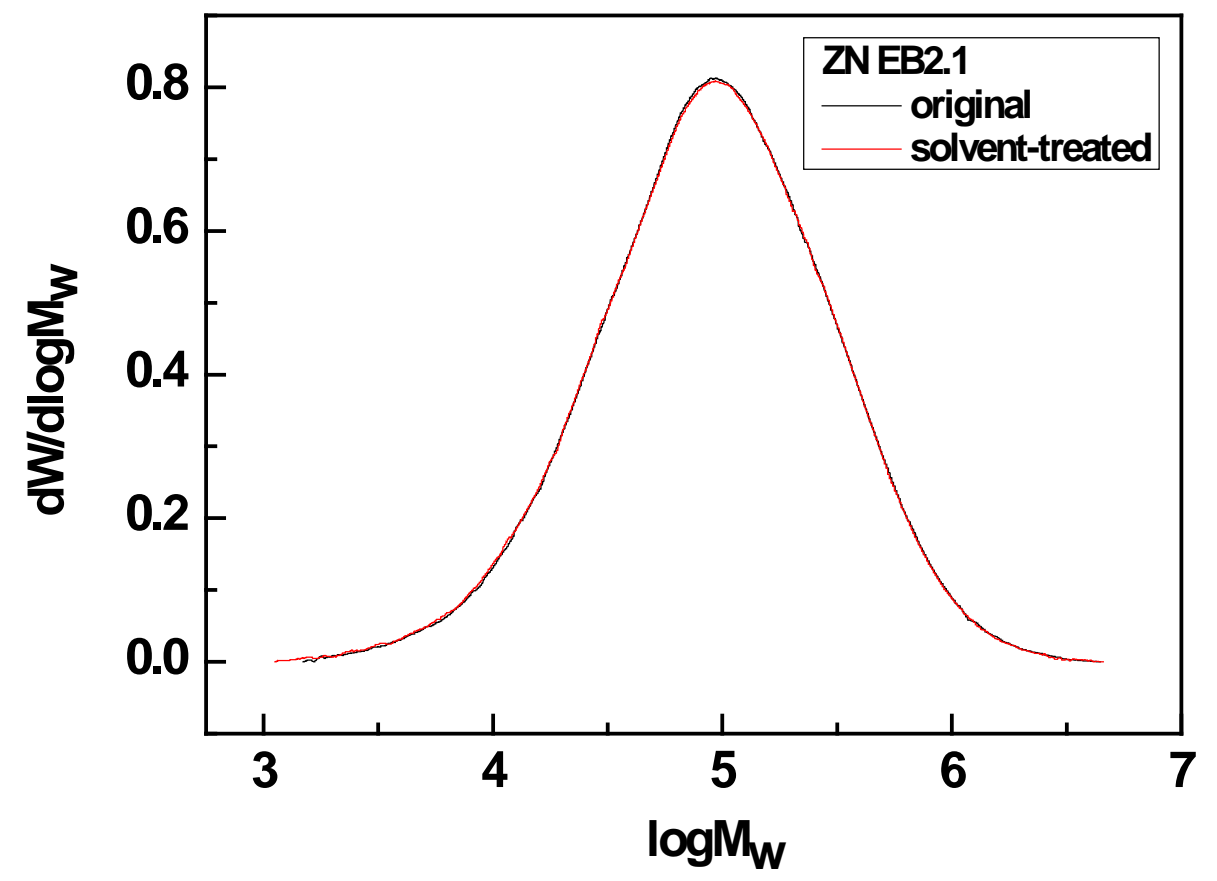

Figure S2. GPC curves of original and solvent treated ZN EB2.1 
The FTIR spectra of the original ZN-LLDPEs and M-LLDPEs are shown in Figure S3. The 1017 $\mathrm{cm}^{-1}$ absorption characteristic of Si-O-Si asymmetric stretching vibration appears in the spectrum of ZN EH1.7 and M EO1.3, indicating that the two samples contain talc, an effective nucleant. ${ }^{\mathrm{i}-i i i}$ The COO- antisymmetric stretching absorbance of the carboxylate group in calcium stearate at $1540 \mathrm{~cm}^{-1}$ and $1577 \mathrm{~cm}^{-1}$ appear in the spectra of ZN EO2.2, ZN EO2.0 and M EO1.3 copolymers, indicating that these samples contain the aid processing calcium stearate. ${ }^{\text {iv }}$ The carbonyl absorbance of the ester group of Irganox at $1740 \mathrm{~cm}^{-1}$ appears in the spectra of most of the original samples except ZN EO2.2 and ZN EO2.0. ${ }^{\mathrm{v}}$ Most ZN and metallocene LLDPEs show a small vinyl absorbance $\left(905 \mathrm{~cm}^{-1}\right)$. ZN EH1.7 shows an absorbance at $965 \mathrm{~cm}^{-1}$ consistent with vinyline groups that becomes prominent after the removal of talc by Soxhlet extraction, as seen in Figure S4 ${ }^{\text {vi }}$
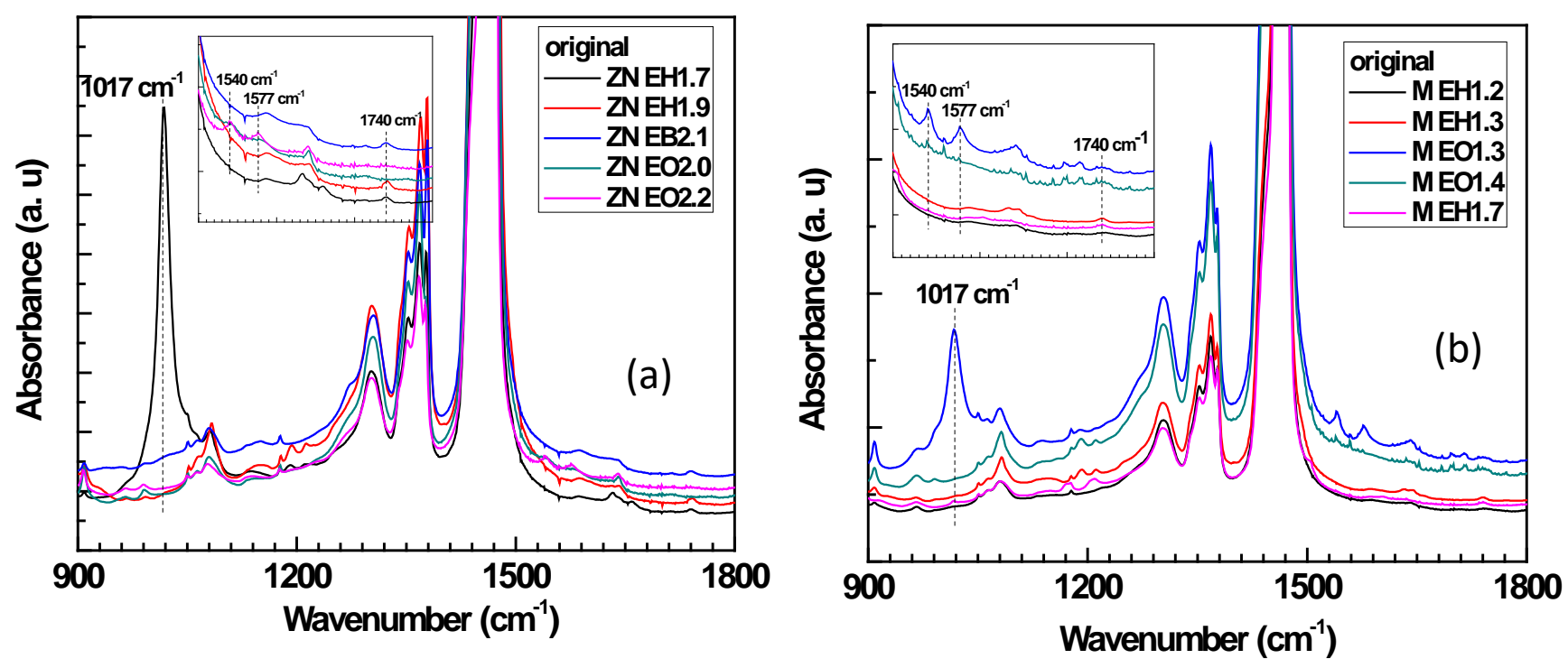

Figure S3. Room temperature FTIR spectra of original (a) ZN-LLDPEs and (b) M-LLDPEs.

The FTIR spectra of the solvent treated or Soxhlet extracted ZN-LLDPEs and M-LLDPEs are shown in Figure S4. The absorption characteristic of Si-O-Si asymmetric stretching vibration of talc, the COO- antisymmetric stretching band of the carboxylate group of calcium stearate, and the ester group of Irganox 1010 are absent, indicating successful removal of these additives after the dissolution and extraction treatments. 

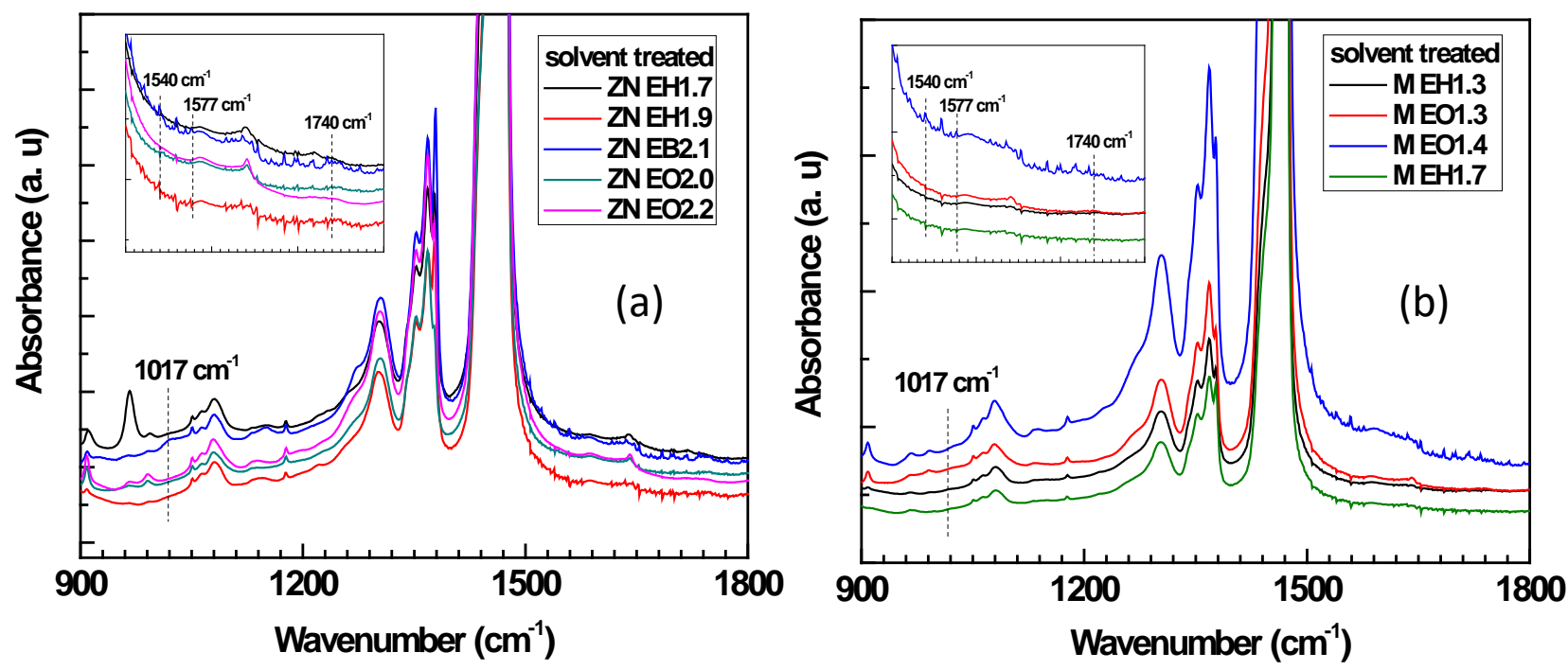

Figure S4. Room temperature FTIR spectra of solvent treated (a) ZN-LLDPEs and (b) M-LLDPEs. 


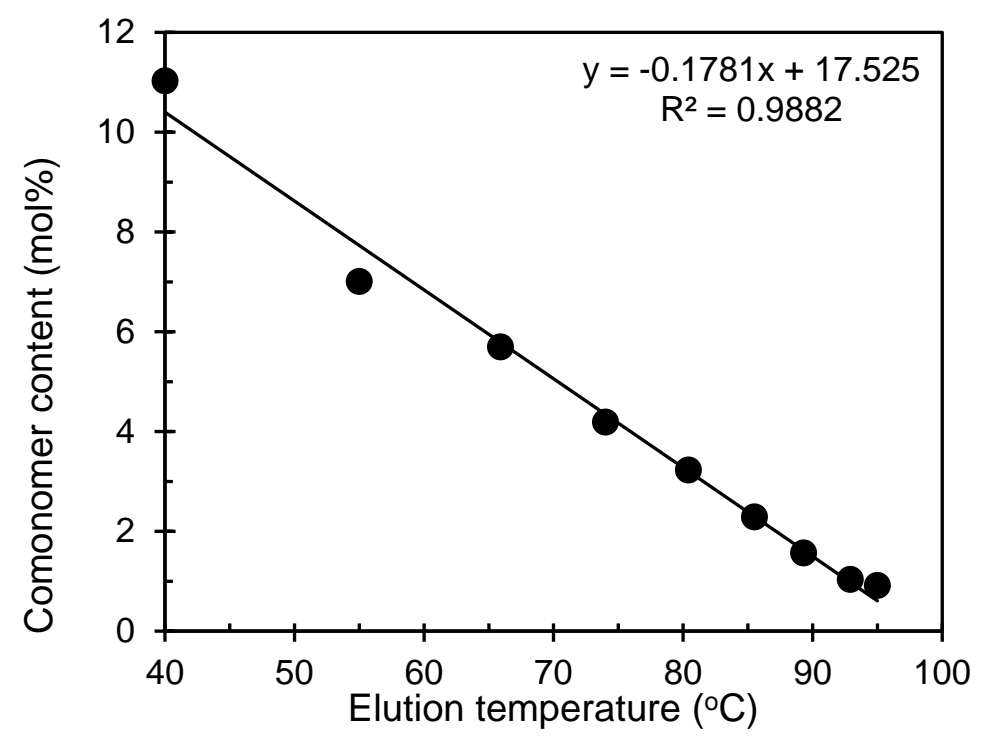

Figure S5. Comonomer content - TREF elution temperature calibration for LLDPEs. Data obtained using 9 fractions from M EH1.7. The comonomer content (mol\%) of each fraction was obtained by solution ${ }^{13} \mathrm{C}$ NMR. ${ }^{\text {vii }}$

\section{REFERENCES}

${ }^{\text {i }}$ Medeiros, E. S. De; Tocchetto, R. S.; Carvalho, L. H. De; Santos, I. M. G.; Souza, A. G. Nucleating Effect and Dynamic Crystallization of a Poly (propylene)/talc System. J. Therm. Anal. Calorim. 2001, 66, 523-531.

ii Naiki, M.; Fukui, Y.; Matsumura, T.; Nomura, T.; Matsuda, M. The Effect of Talc on the Crystallization of Isotactic Polypropylene. J. Appl. Polym. Sci. 2001, 79, 1693-1703.

iii Castillo, L. A.; Barbosa, S. E.; Capiati, N. J. Influence of Talc Genesis and Particle Surface on the Crystallization Kinetics of Polypropylene/Talc Composites. J. Appl. Polym. Sci. 2012, 126, 1763-1772.

iv Deamer, D. W.; Meek, D. W.; Cornwell, D. G. Properties, composition, and structure of stearic acid-stearate monolayers on alkaline earth solutions. J. Lipid Res. 1967, 8, 255-263.

${ }^{v}$ Krimm, S.; Liang, C. Y.; Sutherland, G. B. B. M. Infrared Spectra of High Polymers. II. Polyethylene. J. Chem. Phys. 1956, 25, 549-562.

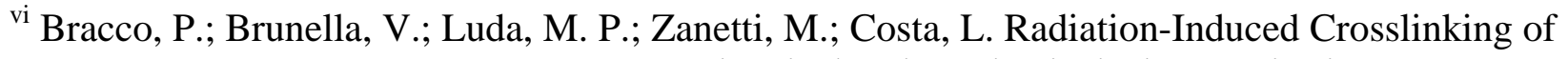
UHMWPE in the Presence of Co-Agents : Chemical and Mechanical Characterisation. Polymer 
2005, 46, 10648-10657.

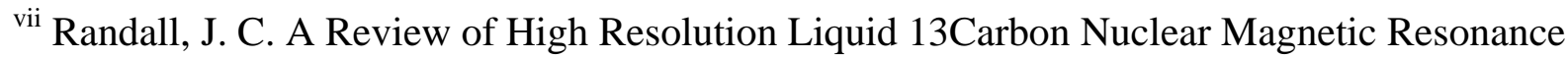
Characterizations of Ethylene-Based Polymers. J. Macromol. Sci., Polym. Rev. 1989, 29, 201-317 